\title{
Robert E Ogilvie: Inventor, MAS Founder, and Educator
}

\author{
J. I. Goldstein ${ }^{1}$ \\ 1. Department of Mechanical and Industrial Eng.,University of Massachusetts, Amherst, MA
}

This year the microanalysis society lost one of its founders, Robert E. Ogilvie. Bob was a major force in microscopy having developed an early version of the electron probe microanalyzer (EPMA). With his student, Victor Macres, he modified a RCA microscope, one of the first EPMA instruments (Fig 1.) In the 1960s a prototype of the Philips commercial instrument (Fig. 2) was developed and heavily used by his students at MIT. He founded the first short course in microscopy with such eminent lecturers as Castaing and Philibert, now the Lehigh SEM Short Course. In addition he was the major thesis advisor of a number of students who contributed to microscopy and instrumentation development (Lyman, Ziebold, Morris, Brown, Goldstein, and others). His major contribution to x-ray microscopy was the development of the "a" factor, Ziebold and Ogilvie (1964) [1] for X-ray microanalysis. In the early 1960s the ZAF method was not well developed and analysis errors were often quite significant. Furthermore, computer data reduction was less generally available. In response to this state of affairs, Ziebold and Ogilvie [1] developed an empirical correction method for quantitative analysis of binary alloys. Using the "a" factor, the intensity ratio sample to standard of element 1 is related directly to the concentration of element 1 in the sample for a given electron beam energy and take-off angle. The popularity of this method increased greatly when it was further developed by Bence and Albee (1968) [2] and applied in geological analysis. The Bence-Albee analytical technique has played an important role in x-ray microanalysis in geology and their paper has been one of the most cited articles in the geological sciences.

Ogilvie was involved in the development of EPASA, the initial professional society which is now called MAS. He organized the "famous" $3^{\text {rd }}$ US microanalysis meeting at the Summerset Hotel in Boston with major support from industrial sponsors. The society social has gone down in history as the best ever with the last attendees (Wittry, Borovsky) leaving on shaky legs after midnight. Ogilvie was president of the society and an active member for many years. He organized the first US-Japan meeting on microanalysis (Fig. 3) in Hawaii and participated in the second meeting a few years later. Among his entrepreneurial efforts, he was a founding member of AMR (Advanced Metals Research Corp), the company which produced and sold the AMRay SEM. In the early days of the firm, many a graduate student manned AMR's several home-made electron probe microanalyzers churning out data for customers.

Bob had wide interests beyond microanalysis, especially meteorites and Japanese swords. In 2000 he was recognized for his meteorite activities with a named minor planet, 3973 Ogilvie. He went to Japan and visited swordmakers to see how swords were made (Fig. 4) and worked with his students on the processing and compositional changes that took place as a result of heat treatment. In retirement he worked part time at the Boston Fine Arts Museum applying x-ray techniques to investigate the detection of art forgeries made available to the museum, the construction of samurai swords, and the analysis of meteorites. He was an avid sailor and used a MIT sabbatical to sail. His sailing activities unfortunately led to a more thorough investigation of the use of MIT faculty sabbaticals. Bob will be missed most for his out of the box thinking, his challenging questions at awkward moments, and his strong support of his students and his family. 
Bob passed away at the age of 89 on September 3, 2013. He is survived by his 3 children Claudia, Mary Lee and Robert. He was a Professor of Metallurgy at MIT in the Department of Materials Science and Engineering for 45 years (Fig. 5).

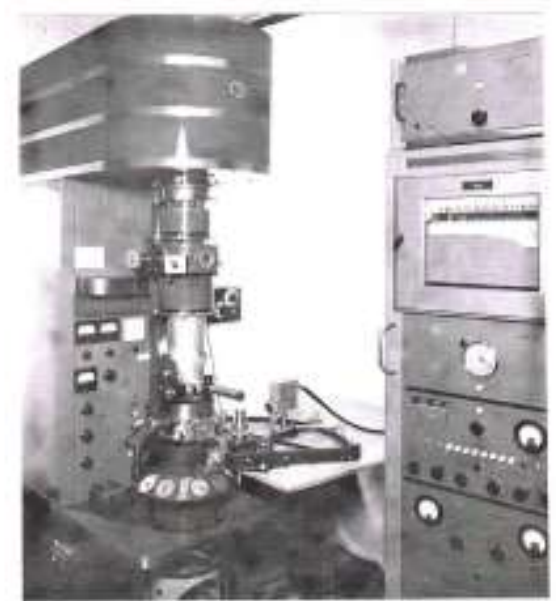

Fig 1. RCA TEM redesigned by Macres and Ogilvie as an EPMA

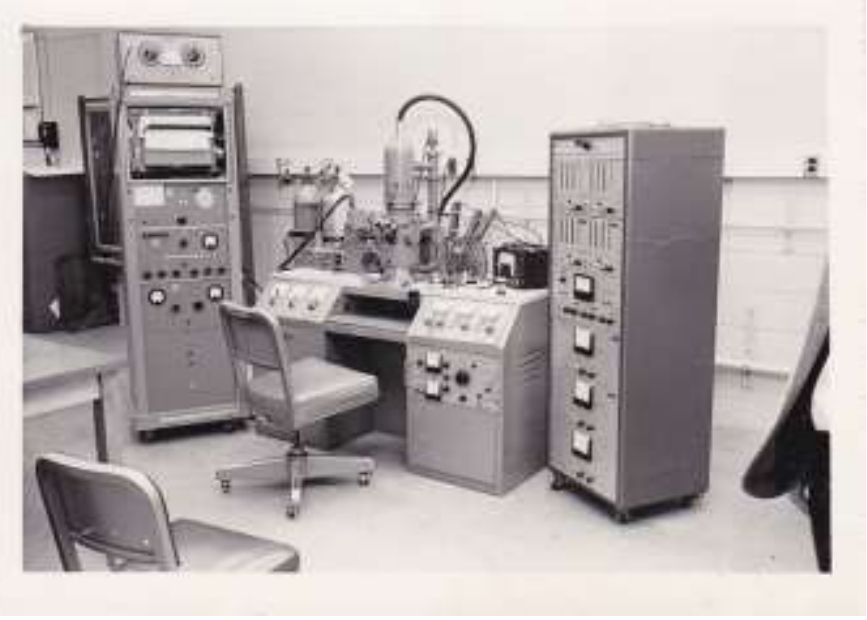

Fig. 2 MIT EPMA, circa 1960

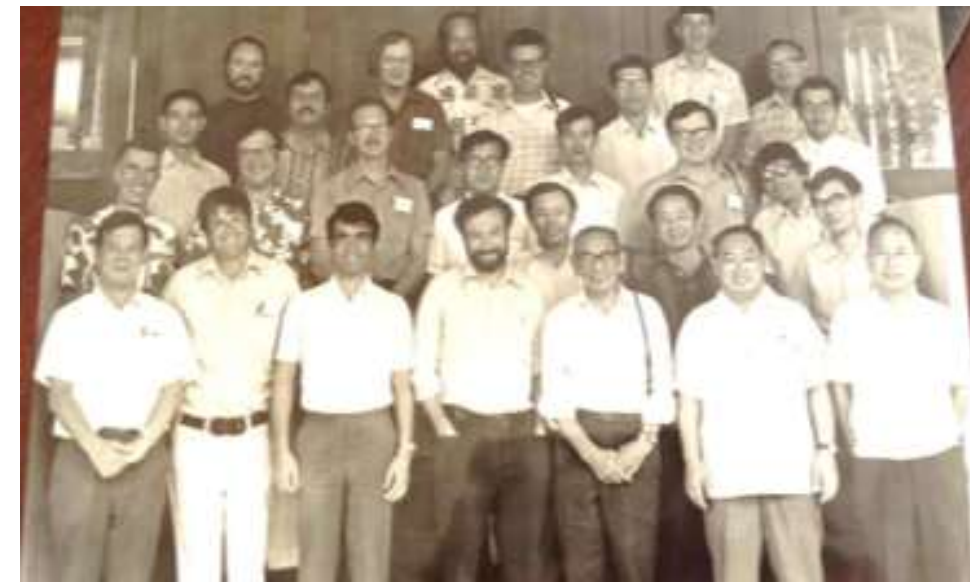

Fig. 3. Attendees of the first US-Japan meeting on Microanalysis, circa 1970

References:

[1] TO Ziebold and RE Ogilvie, Anal. Chem. 36 (1964) p.322

[2] AE Bence and A Albee, J. Geol. 76 (1968) p.382.

[3] The author acknowledges the following for helpful discussions: Tom Ziebold, Dale Newbury, Yet-Ming Chiang, Robert Scott Ogilvie, John Fournelle, and Lanie Gannon

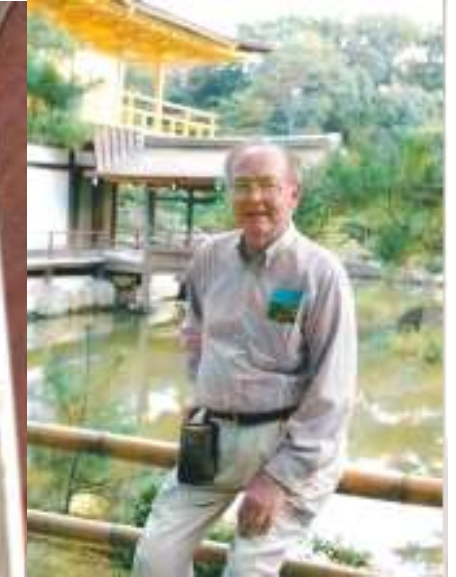

Fig. 4. Bob Ogilvie in Japan

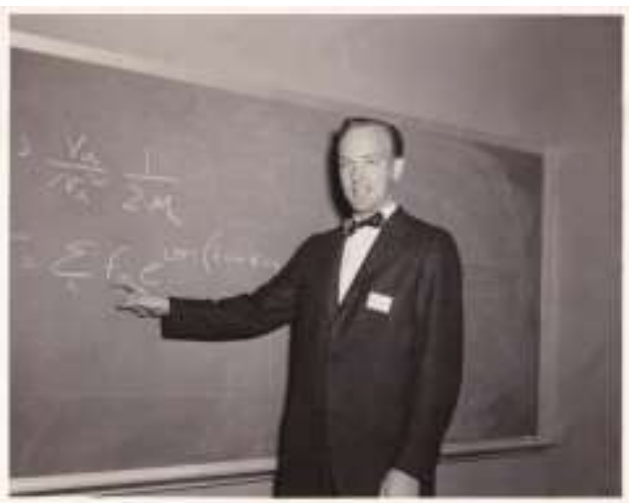

Fig. 5. Robert E Ogilvie, MIT professor 